\title{
LEVERAGING BLOCKCHAIN TECHNOLOGY FOR SMALL BUSINESSES
}

\author{
Mysore Ramaswamy, Southern University, mysore@acm.org
}

\begin{abstract}
Blockchain technology is most likely to change the next decade of business. It enables transfer of digital property from one Internet user to another in a secure way without any intermediaries. The consequences of this breakthrough technology have a vast potential in all areas of business. Information Technology (IT) provides ready to use, end-to-end solutions and allow small businesses to focus on their core business. Recent innovations in IT have positively impacted businesses. With the emergence of blockchain technology, the convergence of telecom and computing is finally reaching maturity in a unified platform for doing business in the $21^{\text {st }}$ century. In this paper, we study the various ways in which blockchain technology can help small businesses and propose a framework that helps in choosing the appropriate blockchain application in the context of business process reengineering.
\end{abstract}

Keywords: Blockchain Technology, Business Process Reengineering, Smart Contracts, Small Businesses

\section{INTRODUCTION}

Information technology provides ready to use, end-to-end solutions and allow small businesses to focus on their core business. Recent innovations in digital technology such as blockchain can play a significant role in spurring the growth of small businesses. Blockchain technology enables transfer of digital property from one Internet user to another in a secure way without any intermediaries. The consequences of this breakthrough technology have a vast potential to positively influence all business enterprises including small businesses. Small and medium scale enterprises account for more than 90 percent enterprises in most OECD (Organization for Economic Cooperation and Development) nations and provide about 80 percent of economic growth (Scupola, 2009). Significant research shows that these businesses contribute to economic growth in multiple ways. Their presence in an economy leads to more competitive large enterprises that can outsource some of their activities to smaller firms. Compared to their relatively small sizes, they create more jobs than large firms (Passerini, 2012). Smaller size is an advantage, particularly in terms of the ability to anticipate and respond to changes and achieve a deeper and closer interaction with the customers.

Information is an important asset that gives small businesses a competitive advantage in the new economy. Information access plays a critical role in the informed decision making process, making it easy for these businesses to make good competitive decisions (Modimogale, 2011). The ability of small businesses to survive in an increasingly competitive global environment is largely predicated upon their capacity to leverage information as a resource. In today's fierce competitive environment, small businesses need to be highly responsive and adaptive to demands of customers, actions of competitors, and changes in economic conditions (Rashaniphon, 2011). Data analytics can be as useful to small businesses by identifying those business processes that are capable of exploiting the new innovations in that area.

This paper is organized as follows. First, we briefly describe the current scenario pertaining to small businesses. This is followed by a brief overview of blockchain technology. The next section proposes a framework that will help adopt the appropriate information technology followed by a section on blockchain applications for small businesses. Concluding remarks form the last section.

\section{SMALL BUSINESSES}

Even though the economic importance of small and medium scale enterprises has been known, they were considered comparatively unimportant during the great Internet boom during the 1990s and early 2000s (Passerini, 2012). Use of broadband information technology required extensive investment in technological assets and a long term access to capital. Such capital requirements were not available to small businesses. Today small businesses can compete and 
excel due to continual improvements in Internet technology as well as breakthroughs in cloud computing and mobile connectivity.

Access to capital and an established brand name are the main advantages of large organizations. One of the greatest advantages small businesses have is flexibility. Many small businesses have a single owner who is free to change policies, and technologies (Sadowski, 2002). For example, the owner of a small grocery store can decide to use broadband to create an automatic reorder system with suppliers. Small businesses can offer new services and change internal processes without having to clear a multitude of committees that would exist in a large organization. Cloud computing, and open source software have brought down the investment requirements and costs. This has resulted in the availability of broadband technologies to small businesses to streamline business processes, grow the customer base, and enlarge existing offerings.

According to Kirchoff's typology (Kim, 2004), small firms can be classified based on two dimensions: innovation and growth as shown in Appendix I. Core firms represent where innovation and growth are low, whereas Glamorous firms have innovation and growth at a high level. Constrained companies have low growth potential but high innovation potential. Ambitious firms have high growth potential but low innovation potential. This paper mostly focuses on Core firms. Mills (2015) classifies small businesses based on types of firms - whether they are sole proprietorships, B2B, etc. - as indicated in Appendix II. Most of the Core small businesses are either sole proprietorships, or local businesses serving consumers and other local businesses. Lower costs of Information Technology (IT) deployment, mobility advantages supported by broadband, and an IT services support system (now directly available as-a-service) can help the more IT conservative small firms (such as 'core' as indicated in Appendix I) to transition to the new mobile apps (Passerini, 2012).

There is a lack of knowledge about the potential benefits of information technology and strategies to support small businesses in achieving their business objectives. Small businesses face the challenge that generally they are owner managed and the owner makes all or most of the decisions about the business (Fillis, 2004; Spencer, 2006). Unfortunately, owner-manager's limitations become limitations of the business. Information technology needs to be considered a key player for the small business in reaching its goals. As information technology is perceived to be expensive by small businesses, they often do not budget for it. The other problem with regard to the cost of IT is that small businesses may invest in unnecessarily big solutions due to sales pitches, hype of specific products or market patterns without considering their real need [Grandon, 2004). Technology is constantly evolving which raises two issues. On the one hand the small businesses need to monitor the kind of technologies that their clients are using and try to make sure that they are ready to serve them. On the other hand, the small businesses s do not need to change every time there is a change in technology as this depends upon the focus area of the small businesses. The competitiveness of a small business depends on the way in which IT is used to support business processes.

\section{BLOCKCHAIN TECHNOLOGY}

The beginnings of blockchain technology go back to a white paper published by S. Nakamoto (2008) where the concept of bitcoin was introduced. Blockchain is a distributed computing architecture that leads to a global database of interfaces and data which will integrate multiple machines and plugin various sources of data (Morabito, 2017). Blockchain technology is built around the theory of "distributed ledger" in which the ledger is stored and maintained on a distributed computer network (Froystad, 2016). The ledger brings about the possibility of the network as a whole to cooperatively produce, develop and record past transactions as well as consecutive digital events.

Blockchain technology is a data store that has the following characteristics:

- It subsists within a decentralized peer-to-peer network,

- Specific users can write it,

- It employs the use of digital signatures and communication security to authenticate user identity,

- Its scheme makes it very difficult to alter historical records,

- Its scheme makes it very easy to detect any attempt to alter historical records,

- Financial transactions are typically a constituent part,

- Specific users and an extensive audience can read it, 
- It is reproduced throughout the network virtually in real-time.

As stated by Zheng (2018), blockchain applications have attracted attention due to the following reasons.

- Decentralization. In a conventional centralized transaction system, each transaction needs to be validated through the central trusted agency (e.g., the central bank) inevitably resulting the cost and the performance bottlenecks at the central servers. On the other hand, a transaction in the blockchain network can be conducted between any two peers (P2P) without the authentication by the central agency. In this manner, blockchain can significantly reduce the server costs (including the development cost and the operation cost) and mitigate the performance bottlenecks at the central server.

- Persistency. Since each of the transactions spreading across the network needs to be confirmed and recorded in blocks distributed in the whole network, it is nearly impossible to tamper. Additionally, each broadcasted block would be validated by other nodes and transactions would be checked. So any falsification could be detected easily. - Anonymity. Each user can interact with the blockchain network with a generated address. Further, a user could generate many addresses to avoid identity exposure. There is no longer any central party keeping users' private information. This mechanism preserves a certain amount of privacy on the transactions included in the blockchain.

- Auditability. Since each of the transactions on the blockchain is validated and recorded with a timestamp, users can easily verify and trace the previous records through accessing any node in the distributed network. In Bitcoin blockchain, each transaction could be traced to previous transactions iteratively. It improves the traceability and the transparency of the data stored in the blockchain.

With reference to small businesses, applications suitable for blockchain technology can be studied under the following three categories: ‘Creating Unbreakable Contracts,' 'Safer Data Storage for an affordable Price,' and 'Reduced Complexity in Supply Chains' (TechHQ, 2019). Businesses deal with contracts on a daily basis. Blockchain can fill up this part of business by creating smart contracts. As the name suggests, smart contracts are self-executed, coded agreements that deliver guaranteed outcomes if the predetermined conditions are met. The significant difference from paper contract is that smart contract is digitized and that it cannot be tampered with in any way because it is in a blockchain.

There are certain advantages in using blockchain for data storage compared to cloud computing. Cloud servers are centralized at the service provider's end and users are legitimately concerned about the possibilities of breaches and cyber-attacks. With blockchain, users can store data in a safer digital space, for a reasonable price. The stored data is encrypted and will only accessible to those who have the crypto-key. Many small businesses will find themselves at some level in a complex supply chain. Shipping and logistics operations can be admin-hevy, resource-swallowing process to organize and keep track of. Blockchain can serve as a central repository for all documents, records, and data relating to shipping and logistics information, with each partner involved able to gain real-time visibility across the entire supply chain they are part of and adjust their operations accordingly.

Small businesses can leverage information technology (IT) in two different ways. One way is to enhance operational support and transaction processing activities. Small businesses adopt and use simple IT innovations without any form of planned strategy to integrate other aspects of business (Qureshil, 2009). In this approach, any form of IT-based competitive advantage is accidental rather than planned. The second way is typically taken to use IT to improve interaction and relationship with customers. A majority of small businesses depend on a small number of customers who purchase large amounts of goods and services. These major customers influence the price of goods and services provided by small businesses. Close relationships among small businesses and customers enable these businesses to respond quickly to any change in customer requirements.

Levy (2001) has proposed an analytical framework that incorporates both forms of strategic focus. In this FocusDominance Model (Appendix III), customer dominance is compared with strategic focus. This framework provides four different strategies to IT adoption. The "Efficiency" quadrant consists of small businesses that exploit simple systems such as word processing and spreadsheets. The "Coordination" quadrant consists of small businesses that have a need to increases market share and their customer base. The "Collaboration" quadrant indicates those small businesses that attempt to incorporate emerging technologies to manage relationships with major customers. The "Innovation:” quadrant consists of those businesses that actively seek to adopt new IT innovations to achieve competitive advantage. 
In a follow-up study, Levy (2002) investigated 43 small businesses to observe their positions in the FocusDominance Model. The results revealed that most of the small businesses make only one move, from "efficiency" to "coordination" or from "efficiency' to "collaboration." Small businesses taking either one of these paths tend to avoid losing control and stay within their current markets. It was also observed that only 17 out of the 43 small businesses wanted to move to the "innovation" quadrant perhaps due to environment scan that indicated possible business growth.

Blockchain technology can be a critical part in business process engineering (BPR) sought by many small businesses. Business process reengineering (BPR) began as a private sector technique to help organizations to fundamentally rethink how they do their work in order to dramatically improve customer service, cut operational costs, and become more competitive (Bogdanoiu, 2014; Dowson, 2015). A key stimulus for reengineering has been the continuing development and deployment of sophisticated information systems and networks. BPR involves changes in structures and in processes within the business environment.

Redesign, retooling, and re-orchestrating form the key components of BPR that are essential for an organization to focus on the outcome that it needs to achieve. The entire technological, human, and organizational dimensions may be changed in BPR. Information technology plays a major role in business process reengineering as it provides office automation, it allows the business to be conducted in different locations, provides flexibility in manufacturing, permits quicker delivery to customers and supports rapid and paperless transactions (Bogdanoiu, 2014; Wu, 2005).

The BPR technique implements organizational change based on rapid change, employee empowerment, and training and support by information technology. In order to implement BPR to an enterprise, the following key actions need to take place:

- Selection of the strategic processes for redesign,

- Simplify new processes - minimize steps - optimize efficiency - modeling,

- Organize a team of employees for each process,

- Organize the workflow - document transfer and control,

- Assign responsibilities and roles for each process,

- Automate processes using information technology,

- Train the process team to efficiently operate the new process,

- Introduce the redesigned process into the new organizational structure.

Applying BPR techniques to small businesses differ substantially from the way large enterprises deal with this issue. BPR concept requires an organization to have a strategy and then set business objective to achieve that strategy. In order to achieve the objective effectively, organization can apply BPR concepts to put the right processes in place (Rashaniphon, 2011; Wailgum, 2009). However, in the case of many small businesses, this classical approach may not be workable. Most of the successful people in small businesses are hands on persons and most likely they do not even bother about the word 'strategy', especially in the business environment of developing countries. It is more effective to try out hands on approach to make changes quickly. They are only looking for short term objectives.

Here are some guidelines that are especially relevant to small businesses (Mansar, 2007):

- Read the market for your business clearly by SWOT (Strengths, Weaknesses, Opportunities, and Threats)

analysis,

- Develop a strategy that optimizes cost, quality, time, and flexibility,

- Execute the developed strategy by strengthening the processes identified for reengineering and without interfering unnecessarily.

Small businesses can leverage techniques and tools that have become increasingly available as open source software such as 'Alfresco' software for content management (Passerini, 2012). Along with the traditional knowledge management processes that include acquisition/creation, storage and retrieval, dissemination and application, SMEs benefit from various size based advantages. For example, in the area of knowledge storage and retrieval, the 
proximity of project teams to the company owner enables quicker and more frequent transactions compared to large organizations.

Appendix IV describes a business model canvas with respect to blockchain technology as suggested by Morukas (2019). In this business model canvas applicable to blockchain, there are nine building blocks covering four main areas of business: its customers, the offer, the infrastructure, and financial viability. The nine building blocks are (1) customer segments, (2) value proposition, (3) channels, (4) customer relationships, (5) revenue streams, (6) key resources, (7) key activities, (8) key partnerships, and (9) cost structure. When taken together and properly aligned, these elements create and deliver value. Key partnerships can take forms such as strategic alliances, joint ventures, or buyer-supplier relationships to ensure reliable supplies. Regarding the cost structure, blockchain implementation can reduce transaction costs and eliminate the costs of intermediaries. The cost savings are the result of a reduction in IT infrastructure costs and the elimination of manual processes that did not add much value to the firm.

\section{FRAMEWORK FOR ADOPTION OF INFORMATION TECHNOLOGY}

Although technology can create new or modified business practices at a rapid rate, successful adoption of new best practices must stand up to market forces. Technology and the marketplace are continually reshaping business activities and as a consequence, business strategies. An organization must continually work towards an alignment that fits into the organization's business strategy and IT strategy. This alignment should improve the likelihood that new initiatives are explicitly linked to areas that are critical to successful business performance, provide a source of competitive advantage. The role of IT should be that of a strategic enabler for competitive success, rather than just an operational supporter.

In the first stage, existing business processes are examined. The number of processes is indeed very large as these pertain to upstream and downstream of the supply chain as well as operations related to the specific business. The gamut of these processes/interactions is also very diverse. The analysis is conducted along the three dimensions of complexity, criticality and cost. Socio-technical factors are considered in the second stage. Not only will this help towards transparency, but it will also make acceptance by constituents easier, Socio-technical factors pertain to exacerbated accountability dysfunctions that can occur as a consequence of automation. According to Bovens (2005) the major categories of dysfunctions are: Rule-obsession, and Proceduralism. Before manual procedures are automated, it has to be ensured that there are no problems due to such dysfunctions.

Rule-obsession or Output-obsession refers to the focus on outcomes over process. 'Proceduralism' refers to increased emphasis on procedures to avoid responsibility and accountability. Strict adherence to procedures cam render the bureaucracy to lose the ability to balance procedures with corporate values. Relying heavily on encoded computer procedures can undermine the effectiveness of organizations.

Processes are restructured in the third stage. Automating legacy procedures that afforded plenty of opportunities for inefficiency will not yield results. At this stage, the results of data analytics are used to modify processes (Mills, 2015; Passerini, 2012). The main objective of restructuring various processes before transforming them into digital interactions is to improve the effectiveness as a system. When automated processes result in disintermediation, it is necessary that the relevant entities are on board with new procedures. After completion of the restructuring stage, we are ready for implementing in the fourth and final stage.

The degree of automation can vary across a wide range. Smith (2010) states a scale of nine degrees of automation starting from the first level where the computer offers no assistance to the ninth level where the computer decides everything. In between these extremes, there are several levels where a varying degree human-computer interaction occurs. The appropriate level of IT intervention depends on the particular interaction that has to be automated.

This framework also provides a means of evaluating extensive (if not comprehensive) series of business process transactions. Depending upon the value of the parameters of the given transaction, we are able to make inferences on the potential of that transaction for potential of IT intervention. This naturally opens up a wide arena of analysis, particularly for others who wish to specialize and focus specifically on the dynamics and characteristics of specific 
interactions where IT intervention is useful. This approach is effective since it focuses on specific critical processes of small businesses and renders overall improvement.

\section{BLOCKCHAIN APPLICATIONS FOR SMALL BUSINESSES}

In this section, we analyze those blockchain applications that are appropriate for small businesses. Research methodology used here combines theoretical findings with empirical findings that results in final recommendations for small businesses regarding use of blockchain applications. The two applications that stand out as most appropriate for small businesses are (i) the use of smart contracts and (ii) reduction of complexity in supply chains.

Businesses deal with contracts such as vendor contracts, payment terms, signing contracts, etc., on a daily basis. Blockchain can fill up this part of business dealings with smart contracts. Smart contracts are self-executed, coded agreements that deliver guaranteed outcomes if the predetermined conditions are met. It is similar to a paper contract where terms are laid out. The difference is the digitization which means that the contract cannot be tampered with in any way because it is in a blockchain. For example, assume that a small business decides to hire the services of a freelance designer to produce advertisements. The firm could discuss and decide on the number of deliverables the designer should produce each month at a set price. Once both parties agree a smart contract can be put in place to facilitate the agreement. For small businesses, this is a risk-free way to manage and regulate relationships with their vendors and subcontractors. Even when applied to a bigger scale, smart contracts do not need a lawyer to facilitate the agreement. As long as conditions are met, transfers can happen without fail.

Many small businesses will find themselves on some rung within a complex supply chain. Functions such as shipping and logistics can be admin-heavy, resource swallowing process to organize and keep track of. With each supply chain partner relying on one another's organization, punctuality, and accuracy, if one part of the chain breaks, as a result of errors or delays, businesses can be affected and damage partner relationships. Blockchain can serve as a central repository for all documents, records, and data relating to shipping and logistics information, with each partner involved able to gain real-time visibility across the entire supply chain they are part of and adjust their operations accordingly. The benefits stated here are some of the most common ways blockchain works for small businesses as agreements and contracts increasingly go online.

\section{CONCLUSION}

Small businesses can benefit from using techniques made available by blockchain technology. New technologies are paving the way for new market creation. As a direct result of this, we have seen new small businesses emerging to cater niche markets as an alternative to impersonal commercial companies. Blockchain technology and business process engineering have been used successfully in the corporate world. However, using these techniques for small businesses can pose some problems. The basic building blocks of IT implementation consist of digitized versions of interactions among various business processes. In this paper, we have presented a framework that can identify and categorize the different types of business processes/transactions. Restructuring these processes and then using the appropriate blockchain application in a systematic way affords a practical approach to leverage blockchain technology. Monitoring the critical success factors will help in evaluating the success of these measures. Future work in this area focuses on developing a comprehensive framework that will enable entrepreneurs and researchers to point out the potential priority areas that can use blockchain applications and also yield a realistic estimate of resources needed to achieve such transformation. In addition, such an approach will also help in giving a better insight into business process restructuring.

\section{REFERENCES}

Bauerle, N. (2017). What is Blockchain Technology? Retrieved March, 14, 2020, from https://www. coindesk.com/learn/blockchain-101/what-is-blockchain-technology

Bogdanoiu, C. (2014). Business Process Reengineering Method. Retrieved March, 14, 2020, from http://www. cesmaa.eu/ awards/ Best Student Paper_BogdanoiuCristiana.pdf 
Brooks, J. A., Treeter, A., and Vinson, S. (2017). Opportunities and Perils: Launching a Small Business. Proceedings of the $47^{\text {th }}$ SEDSI Conference, 424-431.

Davenport, T. H. (2006). Competing on Analytics. Harvard Business Review, 84(2), 98-107.

Davenport, T. H. and J. Harris. (2007). Competing on Analytics. Boston, MA: Harvard Business Review Press.

Dowson, J. (2015). Big Data Analytics and Business Intelligence for Better Customer Experience in Bmall Businesses. Retrieved April, 14, 2018, from http://www.datasciencecentral.com/m/blogpost?id= 6448 529\%3 ABlogPost\%3A316525.

Eckel, E. (2009). Ten Tech Mistakes Small Businesses Make. Retrieved April, 14, 2018, from https: //www.techrepublic.com/blog/10-things/10-tech-mistakes-small-businesses-make

Fillis, I. (2004). Factors Impacting on E-Business Adoption and Development in the Smaller Firm. International Journal of Entrepreneurial Behaviour and Research, 10(3), 178-191.

Frøystad, P, Holm J (2016) Blockchain: powering the Internet of Value, EVRY Labs White Report. Retrieved on May 4, 2020 from https://www.evry.com/globalassets/insight/bank2020/bank-2020 blockchain poweringthe-internet-of-value-whitepaper.pdf.

Grandon, E. E. (2004). Electronic Commerce Adoption: An Empirical Study of Small and Medium US Businesses. Information \& Management, 42(4), 197-216.

Howso, C. (2008). The Road to Making BI Available to Everyone. Information Week, Feb. 25.

Kamal, M. and Jackson, J. (2014). ICTs in Microenterprises: Does it Make a Difference? Proceedings of the Twentieth Americas Conference on Information Systems, 1-10.

Kim, H. M. (2004). Best Practices in E-Business Process Management: Extending a Re-engineering Framework. Business Process Management Journal, 10(1), 17-27.

Lefebvre, L. (2005). Exploring B-to-B E-Commerce Adoption Trajectories in Manufacturing SMEs. Technovation, 25(12), 1443-1456.

Levy, M., and Powell, P. (1998). SME Flexibility and the Role of Information Systems. . Journal of Small Business Economics, Vol. 11, 183-196.

Levy, M., Powell, P., and Yetton, P. (2002). The Dynamics of SME Information Systems. Journal of Small Business Economics, Vol. 19, 341-354.

Levy, M., Powell, P., and Yetton, P. (2001). SMEs: Aligning IS and the Strategic Context. Journal of Information Technology, 16(3), 133-144.

Lu, H. et al. (2019). ICT Implementation of Small- and Medium-Sized Construction Enterprises. Sustainability, 11, 3411, 20 pages.

Mansar, S. L. (2007). Best Practices in Business Process Redesign: Use and Impact. Business Process Management Journal, (13, 2), 193-213.

Mefor, Osita (2017). Why Small Businesses and Nonprofits Need an IT Strategy. Technical Library. 286. Retrieved May, 8, 2019, from http://scholarworks.gsu.edu/cistechlib/286 
Mills, K. (2015). The Four Types of Small Businesses. Harvard Business Review (April).

Modimogale, L. (2011). The Role of ICT within Small and Medium Enterprises in Gauteng. Communications of the IBIMA, Vol. 2011, Article ID 369288, 12 pages.

Morabito, V. (2017). Business Innovation Through Blockchain. Cham, Switzerland: Springer.

Morkunas, V., Paschen, J., and Boon, E. (2019). How Blockchain Technologies Impact your Business Model, Business Horizons, 62(3), 295-306.

Nakamoto, S. (2008). Bitcoin: A peer-to-peer electronic cash system. Retrieved April, 14, 2020, from https://bitcoin.org/bitcoin.pdf.

Passerini, K., A. Tarabishy, and K. Patten. (2012). Information Technology for Small Business. New York, NY: Springer.

Porter, M. (2001). Strategy and the Internet. Harvard Business Review, 79(3), 63-78.

Premkumar, G. (1999). Adoption of New Information Technologies in Rural Small Business. OMEGA International Journal of Management Science, 27(4), 467-484.

Qureshi, S., Kamal, M., and Wolcott, P. (2009). Information Technology Interventions for Growth and Competitiveness in Microenterprises. Internationsl Journal of E-Business Research, 5(1), 117-140.

Rashaniphon, S. (2011). Business Process Reengineering and Thai Small and Medium Enterprises. Proceedings of the International Conference on Management and Service Science, Vol. 8, 69-73.

Raymond, L. (1985). Organizational Characteristics and MIS Success in the context of Small Business. MIS Quarterly, 9(1), 37-52.

Sadowski, B. M. (2002). Strategic Use of the Internet by Small and Medium-Sized Companies: An Exploratory Study. Information Economics and Policy, 14(1), 75-93.

Scupola, A. (2009). SMEs' E-Commerce Adoption: Perspectives from Denmark and Australia, Journal of Enterprise Information Management, 22(1/2), 152-166.

Simon, P. (2013). Even Small Companies Can Tap Big Data if They Know Where to Look. Harvard Business Review, (December 16, 2013).

TechHQ (2019). How can blockchain be used by SMEs? Retrieved on May 26, 2020 from https://techhq.com/2019/08/how-can-blockchain-be-used-by-smes/

Wang, Y, Han, J. and Beynon-Davies, P. (2019). Understanding Blockchain Technology for Future Supply Chains: a Systematic Literature Review and Research Agenda. Supply Chain Management: An International Journal, 24 (1), pp. 62-84.

Wu, F. (2005). An Analysis of E-Business Adoption and Its Impact on Business Performance. Journal of the Academy of Marketing Science, 31(4), 425-447.

Zheng, Z. and Dai, H. (2018). Blockchain Challenges and Opportunities. International Journal of Web and Grid Services, 16(4), 352-375.

Zhu, K. (2002). E-Commerce Metrics for Net-Enhanced Organizations: Assessing the Value of E-Commerce to Firm Performance in the Manufacturing Sector. Information Systems Research, 13(30), 275-295. 
Appendix I. Kirchoff's Typology of Small Firms [Adapted from (Passerini, 2012)]

\begin{tabular}{|l|l|}
\hline $\begin{array}{l}\text { CONSTRAINED } \\
\text { Low Growth }\end{array}$ & $\begin{array}{l}\text { GLAMOROUS } \\
\text { High Innovation } \\
\text { High Growth }\end{array}$ \\
\hline CORE & \\
$\begin{array}{l}\text { Low Innovation } \\
\text { Low Growth }\end{array}$ & $\begin{array}{l}\text { AMBITIOUS } \\
\text { Low Innovation } \\
\text { High Growth }\end{array}$ \\
\hline
\end{tabular}

Appendix II. Types of Small Businesses [Adapted from (Mills, 2015)]

\section{The Four Main Types of Small Businesses}

\begin{tabular}{|c|c|c|}
\hline TYPES OF FIRMS & NUMBER OF FIRMS* & DESCRIPTION \\
\hline $\begin{array}{l}\text { Non-Employee } \\
\text { Businesses }\end{array}$ & 23 million & Sole proprietorships \\
\hline Main Street & 4 million & $\begin{array}{l}\text { Local businesses serving consumers and } \\
\text { other local businesses }\end{array}$ \\
\hline Suppliers & 1 million & $\begin{array}{l}\text { Suppliers to other businesses (B2B) } \\
\text { in the traded sector }\end{array}$ \\
\hline High-Growth & 200,000 & Fast-growing, innovation-driven businesses \\
\hline
\end{tabular}


Appendix III. Focus-Dominance Model [Adapted from (Qureshi, 2009)]

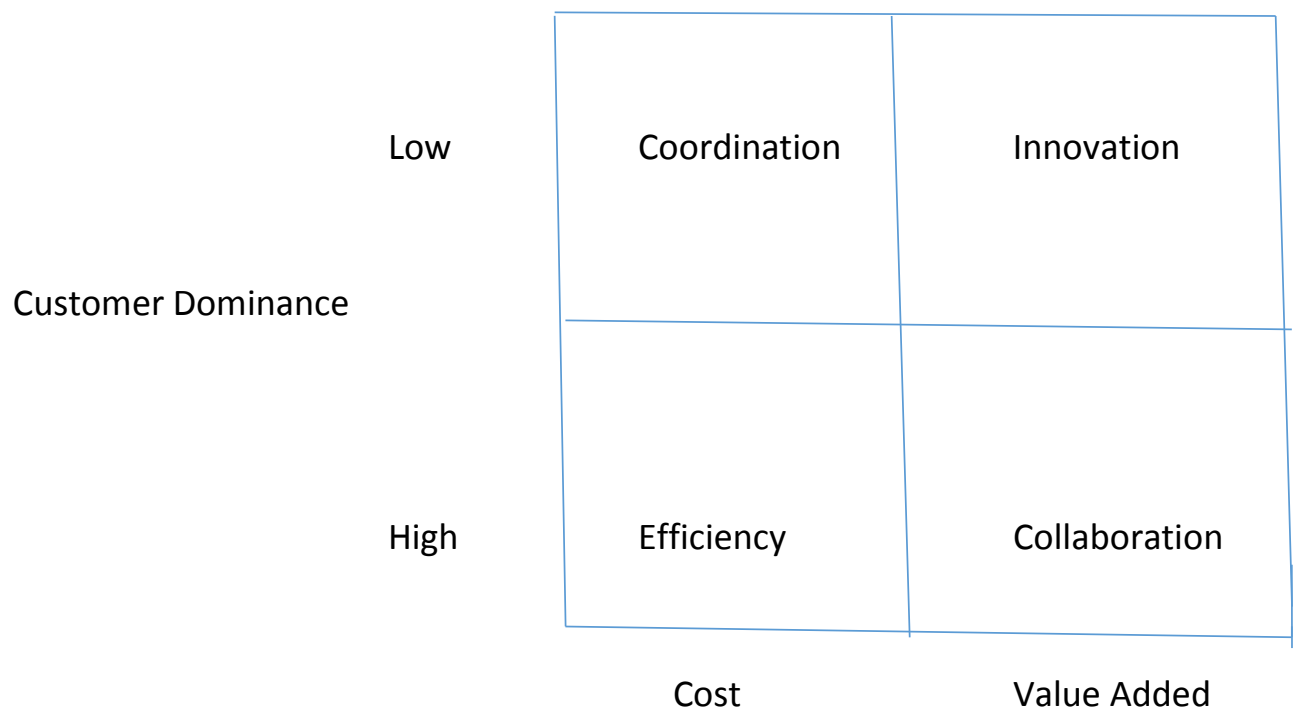

Strategic Focus

Appendix IV. The Blockchain and the Business Model Canvas [Adapted from (Morkunas, 2019)]

\begin{tabular}{|c|c|c|c|c|}
\hline \multirow{2}{*}{$\begin{array}{l}\text { Key Partnerships } \\
\text { - Strengthened company } \\
\text { ties inside the supply } \\
\text { chain } \\
\text { - Strengthened data } \\
\text { integrity } \\
\text { - Facilitation of Payments } \\
\text { - Shared Networks } \\
\text { - Elimination of lengthy } \\
\text { processes }\end{array}$} & $\begin{array}{l}\text { Key Activities } \\
\text { - Transform business } \\
\text { processes } \\
\text { - Peer-to-peer } \\
\text { networks }\end{array}$ & \multirow{2}{*}{$\begin{array}{l}\text { Value Proposition } \\
\text { - Verifiability } \\
\text { - Access new } \\
\text { products or services } \\
\text { - Faster transactions } \\
\text { - Less expensive } \\
\text { transactions } \\
\text { - Smart contracts, } \\
\text { fewer middle layers }\end{array}$} & $\begin{array}{l}\text { Customer } \\
\text { Relationships } \\
\text { - Greater } \\
\text { transparencies } \\
\text { - Self-service } \\
\text { - Automation } \\
\text { - No middlemen }\end{array}$ & \multirow[t]{2}{*}{$\begin{array}{l}\text { Customer } \\
\text { Segments } \\
\bullet \text { Reach new } \\
\text { customers } \\
\text { - Reach new } \\
\text { customer } \\
\text { segments }\end{array}$} \\
\hline & $\begin{array}{l}\text { Key Resources } \\
\text { Access via peer-to- } \\
\text { peer networks. } \\
\text { Improvements in } \\
\text { - Verification } \\
\text { - Documentation } \\
\text { - Audits } \\
\end{array}$ & & $\begin{array}{l}\text { Channels } \\
\text { - New channels } \\
\text { - New APIs, } \\
\text { SDKs }\end{array}$ & \\
\hline \multicolumn{3}{|c|}{$\begin{array}{l}\text { Cost Structure } \\
\text { - Reduced search costs } \\
\text { - Reduced negotiation costs } \\
\text { - Reduced IT costs } \\
\text { - Reduced transaction costs } \\
\text { - Increased costs of IT/software, development personnel }\end{array}$} & \multicolumn{2}{|c|}{$\begin{array}{l}\text { Revenue Streams } \\
\text { - Recurring revenues } \\
\text { - Transaction revenues } \\
\text { - Services revenues } \\
\text { - Crowdfunding }\end{array}$} \\
\hline
\end{tabular}

